\title{
ESTUDO SOBRE GÊNERO E RAÇA: MOBILIDADE NO TRIBUNAL DE JUSTIÇA DO ESTADO DE SÃO PAULO
}

\author{
STUDY ON GENDER AND RACE: MOBILITY IN THE COURT OF JUSTICE OF THE \\ STATE OF SÃO PAULO
}

\author{
Renata Miranda Lima \\ Mestre em Direito Justiça e Sustentabilidade pela Universidade Nove de Julho \\ renatamirandalima@yahoo.com.br

\begin{abstract}
Luciana de Toledo Temer Lulia
Doutora em Direito Constitucional pela Pontifícia Universidade Católica de São Paulo lutemer@uol.com.br
\end{abstract}

\begin{abstract}
Resumo: Esta pesquisa busca compreender como se materializa o Direito à Igualdade, tendo como fundamento raça e gênero no campo de estudo TJ-SP entre o período de 1997 a 2017. Para tanto, a metodologia empregada, utiliza pesquisa bibliográfica e documental, estudo de caso no TJSP e análise estatística por meio de dados do Conselho Nacional de Justiça - CNJ e -TJ-SP. Tem-se com resultado do estudo que, a mulher, em especial a mulher negra, experienciam barreiras históricas refletidas na Constituição que se caracterizam como resquício mantenedor de desigualdades na concretização da mobilidade a cargos de poder. Nesta toada, o estudo permite considerar que é necessário um olhar atento ao Direito à Igualdade para que este não seja visto meramente a partir das lentes da igualdade formal, mas sim material. Portanto, é imprescindível a criação de políticas públicas desenhadas e implementadas tendo como protagonistas o segmento social a qual se dirige estas políticas.
\end{abstract}

Palavras-chave: Direito à igualdade. Espaços de poder. Gênero. Raça. Tribunal de Justiça do Estado de São Paulo.

Abstract: This research seeks to understand how the Right to Equality materializes, based on race and gender in the field of study TJ-SP between 1997 and 2017. For this purpose, the methodology used, uses bibliographic and documentary research, case study in TJSP and statistical analysis using data from the National Council of Justice - CNJ and -TJ-SP. As a result of the study, women, especially black women, experience historical barriers reflected in the Constitution, which are characterized as a remnant of inequalities in the realization of mobility to positions of power. In this light, the study allows us to consider that a close look at the Right to Equality is necessary so that it is not seen merely through the lens of formal equality, but material. Therefore, it is essential to create policy publics designed and implemented with the social segment to which these policies address as protagonists.

Keywords: Right to equality. Spaces of power. Genre. Race. Court of Justice of the State of São Paulo.

\section{Para citar este artigo}

ABNT NBR 6023:2018

LIMA, Renata Miranda; LULIA, Luciana Toledo Temer. Estudo sobre gênero e raça: mobilidade no Tribunal de Justiça do Estado de São Paulo. Prisma Jurídico, São Paulo, v. 19, n. 1, p. 2-22, jan./jun. 2020. http://doi.org/10.5585/prismaj.v19n1.14254. 


\section{Introdução}

A Constituição brasileira prevê no seu artigo 93 as formas de ingresso na magistratura, assim como, estabelecem a promoção na carreira por meio da antiguidade no cargo e merecimento aferidos por meio de critérios objetivos de produtividade e eficiência.

O retrato da magistratura que compõem o Poder Judiciário do Estado de São Paulo, segundo os dados fornecidos pela própria instituição referentes ao ano de 2017, configurou-se na primeira instância por 1.184 juízes atuantes na capital e 1.363 prenotados no interior totalizando 2.547 juízes em atividade (SIC-TJ/SP, 2017).

Dentre os magistrados com labor na capital, tem se que 340 são juízes e 373 são juízas. Por sua vez, entre as magistradas, 16 delas se autodeclaram pardas e negras. Em relação a segunda instância a configuração se altera para o seguinte desenho: 61 juízes e 21 juízas na condição de substitutos; 361 desembargadores, 28 desembargadoras com destaque para o fato de 4 delas se declaram negras.

Este cenário evidencia uma sociedade marcada por desigualdades, entre elas, a de gênero e a do racismo estrutural e institucionalizado como freios determinantes à mobilidade social das mulheres, em especial às negras. A situação do TJ-SP reflete esta realidade, quando se verifica que o número de mulheres na primeira instância supera o número de homens, mas que o quadro se inverte quando se analisa os números da segunda instância, que revela o triplo de homens em relação às mulheres entre os juízes substitutos. A situação toma maior proporção quando se compara o número de desembargadores. Segundo os dados, 92,80\% são do sexo masculino, enquanto $7,19 \%$ são de mulheres. Cabe ressaltar que $1 \%$ corresponde às mulheres negras.

No presente estudo, a concretização do Direito à Igualdade é verificada a partir das possibilidades de Mobilidade igual aos quadros do TJSP, tendo como fundamento gênero e raça. A partir da delimitação do campo de estudo, considera-se que o Direito à Igualdade é concretizado quando se verifica um espaço plural e diverso.

A este respeito, reputa-se que a pluralidade e a diversidade nos quadros do TJSP têm sua importância ampliada, especialmente na sociedade brasileira, em razão dos diversos problemas de justiça social.

Nesta toada, a promoção de representatividade de diversos segmentos sociais na magistratura de primeira e segunda instância, ensejaria resultados altamente positivos em dois aspectos: representaria inclusão e promoveria maior pacificação social em razão do sentimento de representatividade, por que as respostas também seriam construídas por grupos 
que são historicamente marginalizados e excluídos do exercício da cidadania, espaços de poder e decisão.

Ante o exposto, o presente artigo se propõe refletir a necessidade de inclusão à primeira instância da magistratura de grupos socialmente marginalizados e a mobilidade social das magistradas ao TJ-SP, aos cargos de cúpula e de decisão, visto que mulheres alcançaram igualdade na magistratura de primeira instância.

Contudo, grupos marginalizados como mulheres negras, indígenas, pessoas Trans e pessoas com deficiência, não alcançaram igualdade nas carreiras da magistratura na primeira e segunda instância. Assim, a alguns segmentos sociais é dada ênfase a necessidade de mobilidade dentro da carreira, visto que já alcançaram acesso equânime nos escalões de base. Contudo, aos grupos marginalizados, considera-se necessária a implementação de políticas à inclusão na magistratura, para após se pensar em mobilidade dentro da carreira visto que sobre estes recaem entraves interseccionados que transcendem os de gênero e inviabiliza o acesso equânime à carreira.

As diferenças verificadas nos dados transcritos acima são decorrentes de diferentes intersecções de violências que atravessam os grupos sociais e estes por si só, já seriam suficientes para desencadear uma série de estudos tratando do tema. Neste cenário, pode-se asseverar que, para além da discrepância entre o número de desembargadores homens e mulheres, resta evidente outra desigualdade social referente a raça em que sobrepõem impedimentos especialmente às mulheres negras e indígenas de ocuparem lugares nas esferas de poder.

Neste ínterim, o presente artigo se desenvolve da seguinte forma: Em um primeiro momento tece considerações quanto ao acesso a direitos sobre a perspectiva de gênero. Após é refletido como mulheres alcançaram a magistratura procurando responder por que há poucas na segunda instância do TJ-SP. Na sequência, o estudo se dirigirá a compreender as intersecções de gênero e raça que geram entraves no acesso e mobilidade dentro da magistratura Paulista.

Tecidas essas considerações, o artigo passará a refletir o critério legal de antiguidade e merecimento para a promoção/mobilidade de carreira no TJSP, levando em conta o Direito à Igualdade, correlacionando o cenário atual com o contexto histórico de discriminação em razão de gênero e raça. 


\title{
1 A Construção Do Feminino Na Sociedade: Direito À Igualdade
}

\author{
Ser um homem feminino \\ não fere o meu lado masculino \\ se Deus é menina e menino \\ sou masculino e feminino \\ Olhei tudo que aprendi \\ e um belo dia eu vi \\ Que ser um homem feminino \\ não fere o meu lado masculino
}

(Pepeu Gomes)

A presente canção é um convite à reflexão do que é feminino e masculino, conduzindo a questionamentos quanto às construções binárias que, impõe não apenas comportamentos, mas também posições sociais e diferentes possibilidades de acesso à direitos.

Estas reflexões passaram a emergir na sociedade e ganhou maior contorno com o movimento social organizado na chamada, primeira onda do feminismo a partir das últimas décadas do século XIX nomeados 'sufragistas' (PINTO, 2010, p. 1).

Contudo, Joan W. Scott adverte que o conceito de gênero não se reduz ao conhecimento em relação a um suposto masculino ou feminino. Entretanto, com o passar do tempo o termo se cristalizou e foi cooptado para servir como sinônimo de mulher, sexo, papéis sexuais. Neste ínterim, compreende-se necessário movimento contrário para romper com uma gramática que opera de forma binária, reduzindo as diversas formas de identidade, desigualdades e suas intercessões de violências; redefinido e reestruturado em conjunção com a visão de igualdade política e social que inclui não só o sexo, mas também a classe e a raça a ideia de gênero abarcando assim, outras formas de ser e existir (SCOTT, 2010, p. 29).

Destarte, Simone de Beauvoir no livro 'O segundo sexo', considera que tais relações são relações de poder (BEAUVOIR, 1970, p. 10). Portanto, entendê-las apenas a partir da ideia do feminino e masculino é considerada, no mínimo equivocada por Silva (2009, p. 166), que afirma não existir uma essência masculina inerentemente viril, ou uma essência feminina de fraqueza e angelicalidade inata à mulher, mas sim diversas formas de ser e existir no mundo. No entanto, a crença nesta concepção coopera para a manutenção da opressão e dominação contra os grupos sociais marginalizados.

Desse modo, considera-se que a sociedade define os direitos e papéis sociais de cada ser humano. No caso da civilização ocidental, o suposto feminino é construído e valorado a partir da ideia do suposto homem e a história do Gênese, o qual simboliza a humanidade a partir da figura masculina, pois a mulher é definida a partir do homem não como ser autônomo, pois é extraída do homem. Para Beauvoir, há de se estabelecer esforços para 
desmascarar e desconstruir a ideia de superioridade do masculino em detrimento do feminino que historicamente se tornou natural (Op. Cit., 1970, p. 10).

Essa construção de papéis sociais, aos poucos foi perdendo espaço em razão do muito esforço das mulheres que lutavam por igualdade de tratamento. No Brasil, essas lutas resultaram na conquista do direito à educação superior, a qual se deu no final do século XIX, pelo Decreto número 7.247, de abril de 1879, editado por Dom Pedro II.

Outra conquista foi o direito ao voto, sem distinção de sexo, em 1932, estabelecido no Decreto $n^{\circ} 21.076$ (BRASIL. CE, 1932), pelo então presidente Getúlio Vargas. Dentro desse contexto, é importante ressaltar que, apesar da mulher ter sido alijada do direito à cidadania por tempos, segundo dados do Tribunal Superior Eleitoral, o eleitorado feminino Brasileiro, em 2016, correspondia a 52\% dos cidadãos, ou seja, mais da metade. Entretanto, quando se questiona onde estão essas mulheres, percebe-se que as desigualdades implantadas se reproduzem de forma sofisticada o que é corroborado na necessidade, ainda hoje, de exigir paridade de gênero nas candidaturas e apesar da exigência legal e do eleitorado feminino ser majoritário, dados estatísticos mostram que o número de candidatas mulheres nas eleições municipais de 2016 , foi de $31,89 \%$ e essa foi a primeira vez que as candidaturas femininas alcançaram 30\% do total de candidaturas de um pleito no país (BRASIL.TSE, 2016).

Essa desigualdade não é diferente em outras instâncias de poder como, por exemplo, o Conselho Federal da Ordem dos Advogados do Brasil que até julho de 2018 contava com 531.706 advogadas e 562.321 advogados, entretanto apenas homens exerceram a presidência ou cargos de cúpula na $\mathrm{OAB}(\mathrm{CFOAB}, 2018)$ e ainda no próprio exercício da advocacia conforme estudo, verifica-se o fenômeno da feminização da carreira em que cabe às mulheres as atividades mais tradicionais e rotineiras e aos homens as áreas especializadas e inovadoras reproduzindo assim, a divisão sexual do trabalho (BONELLI, 2008, p. 267).

Diante do exposto, percebe-se que as amarras legais e sociais refletem nas posições sociais quando estudadas sob o enfoque de gênero. Quanto à opressão dirigida à mulher negra, verifica-se que sobre estas recai o forte peso da raça e do racismo além das questões de gênero.

Para uma aproximação mais atenta às relações de raça no Brasil, é imprescindível o estudo da história brasileira. Nesse ínterim, verifica-se que as "relações entre europeus, indígenas e africanos foram marcadas por distinções de cunho racial" que podem ser destacadas ora nos argumentos espirituais, biológicos e médicos, e até mesmo pelo senso comum senhorial em que: 
Negros e indígenas eram classificados e reclassificados ao olhar do europeu de forma radicalizada, isto é, de forma a estabelecer distinções entre esses três grandes grupos, não apenas com um sentido de hierarquização, mas de definição do que era ou não considerado humano (Op. cit., 2018, p. 417).

Esse processo de racialização sobre a população negra perfilhou o período escravocrata e definiu diferenças de acesso a direitos. No que tange a educação, a população negra ficou durante anos inviabilizados de ter acesso, pois o regulamento 22 de agosto de 1887 da província do Estado de São Paulo dizia no seu artigo $143 \S 5^{\circ}$ que: Não serão admitidos à matrícula nas escolas de primeira cathegoria: Os escravos, salvo nos cursos noturnos e com consentimento dos senhores (SÃO PAULO, 1887).

Como consequência, a população negra em sua grande maioria era analfabeta e assim, impedida do exercício da cidadania, pois segundo o Decreto $\mathrm{n}^{\circ} 21.076$ de 1932, artigo $4^{\circ}$ "b" não podem alistar-se eleitores analfabetos (BRASIL, 1932).

No que diz respeito às relações de trabalho e a implantação do modelo econômico capitalista no Brasil, Florestan Fernandes (2008), destaca que com a abolição da escravidão a integração da população negra na sociedade de classe fora permeada por diversas complexidades, uma vez que a massa de trabalhadores a ser absorvida pela organização de mercado era composta por nacionais, estrangeiros e os negros recém-livres.

Neste contexto, a inserção do negro na sociedade de classe se deu de forma abrupta, uma vez que o desfazimento do regime escravocrata e senhorial aconteceu sem que houvesse a destituição dos:

\footnotetext{
Antigos agentes de trabalho escravo, de assistência e garantias que os protegessem na transição. Os senhores foram eximidos da responsabilidade pela manutenção e segurança dos libertos, sem que o Estado, a igreja ou qualquer outra instituição assumisse encargos especiais que tivesse por projeto prepará-los para um regime de organização de vida e de trabalho.
}

Assim, o "antigo agente do trabalho escravo imprimiu à abolição o caráter de uma espoliação extrema e cruel" (Ibidem, 2008, p. 29).

No que concerne ao exposto, considera-se que a liberdade conferida despida de mecanismos de promoção de igualdade material é ponto chave à continuação de uma estrutura que inviabiliza a integração do negro na sociedade de classe. Portanto, a ausência de garantias e assistência foram instrumentos de perpetuação de desigualdades, em que apesar de se conferir liberdade ao escravo, os antigos agentes da escravidão que mantinham a condição de não acesso aos direitos, continuava a inviabilizar este acesso à população negra diante da ausência de mecanismos de promoção de igualdade. 
Em consonância com o exposto, Joaquim Nabuco observa que o período escravocrata marcaria por longo tempo a sociedade brasileira, porque a abolição não fora seguida de medidas sociais que conferissem igualdade política, econômica e social aos recém-libertos (NABUCO, 2000, p. 14).

Por sua vez, Sueli Carneiro aponta que essas marcas se seguiram em razão do racismo científico do século XIX que legitimou a divisão de raças na humanidade estabelecendo hierarquia entre elas, conferindo status de inferioridade e superioridade naturais (CARNEIRO, 2011, p. 16).

Para Florestan Fernandes, os resquícios da escravidão se perpetuaram porque "a legislação, o poder público e os círculos politicamente ativos da sociedade se mantiveram indiferentes e inertes diante de um drama material e moral que sempre fora reconhecido e previsto" no que diz respeito à população negra recém liberta (FERNANDES, 2008, p. 31).

Sueli Carneiro ao trabalhar raça e Direitos Humanos no Brasil observa que "a base da contradição de população liberta, mas sem direitos", se conserva "pela prevalência da concepção de que certos humanos são mais ou menos humanos do que outros o que, consequentemente, leva a naturalização da desigualdade de direitos.” A autora observa que "se alguns estão consolidados no imaginário social como portadores de humanidade incompleta, torna-se natural que não participem igualmente do gozo pleno de Direitos Humanos" (Op. Cit. p. 15).

Nesta toada, Leonardo Ortegal (2018), afirma que a ideia de menos humano é elemento importante para compreender as relações sociais no Brasil, "pois, em um mundo marcadamente antropocêntrico, caracterizar determinado grupo como não humano ou subhumano resultava em total isenção moral para a exploração, escravização e extermínio desse grupo assim classificado". Segundo este autor,

\footnotetext{
'isto está evidenciado nos mais diversos estudos da historiografia e da sociologia do Brasil e não teve seus efeitos suspensos por decreto, como a promulgação da Lei Áurea ou da Proclamação da Independência' e os reflexos dessa desigualdade racial ainda repercutem na contemporaneidade e se encontra viva no ideário social (Ibidem, 2018, p. 47).
}

Daí a necessidade de se pensar em formas de promoção de acesso interseccionando gênero e raça para compreender as desigualdades de acesso que atingem as mulheres negras no acesso e mobilidade dentro dos cargos de cúpula no TJ-SP.

Sob um prisma jurídico, reunindo as reflexões referentes ao gênero e raça no que tange ao Direito à Igualdade, Norberto Bobbio explica que, as pessoas ora buscam fundamento para 
um direito que se têm; ora buscam fundamento para um direito que gostariam de ter. No primeiro caso o fundamento é encontrado no ordenamento jurídico positivo válido; no segundo caso, se buscará boas e fortes razões que fundamentam a defesa e legitimidade daquele direito em questão, a fim de convencer o maior número de pessoas possíveis ao seu reconhecimento. O primeiro é direito positivo; o segundo encontra fundamento no direito natural (BOBBIO, 2004, p. 12).

A partir dessa compreensão, tem-se que o Direito à Igualdade encontra fundamento na Constituição Federal de 1988 no artigo $3^{\circ}$ inciso IV, ao dispor que é objetivo fundamental da República Federativa do Brasil “[...] promover o bem de todos, sem preconceitos de origem, raça, sexo, cor, idade e quaisquer outras formas de discriminação” (BRASIL, CRFB, 1988).

Reafirma o direito à igualdade o artigo $5^{\circ}$, caput, ao estabelecer que: "todos são iguais perante a lei, sem distinção de qualquer natureza, garantindo-se aos brasileiros e aos estrangeiros residentes no País a inviolabilidade do direito à vida, à liberdade, à igualdade, à segurança e à propriedade, nos termos seguintes [...]" e no inciso I, segue dizendo: "[...] homens e mulheres são iguais em direitos e obrigações, nos termos desta Constituição" (Idem).

Nesta toada, verifica-se que em muitos momentos da Carta Cidadã, o constituinte desiguala pessoas e situações justamente para atender ao princípio da igualdade material, com uma irrefutável preocupação em promover igualdade entre sexo e raça. Tal atenção é motivada por antecedentes históricos que ainda repercutem nas relações em sociedade.

Apesar da previsão Constitucional de igualdade entre os sexos e raça, se mantém dia após dia a criação, outrora feita, de dois mundos que determinam o viver desses sujeitos. Essa determinação de papéis sociais, histórica e culturalmente estabelecidos, é uma das formas de violência que atravessam às mulheres e às mulheres negras desigualando as possibilidades de acesso a determinados espaços. .

Neste contexto, considera-se que determinantes sociais se revelam como travas interseccionalidades a ascensão social feminina e tem com tese que tais entraves também se espraiam para as instituições e órgãos do Estado como o TJ-SP, pois recebe forte influência proveniente de nossa sociedade sensivelmente marcada por desigualdades de gênero e raça na construção de papéis sociais.

Diante da reflexão teórica tecida acima, mostra-se importante verificar o que os dados apontam, com a finalidade de compreender onde as mulheres estão nos cargos da magistratura, e quem são essas mulheres. 


\title{
2 Mulheres no Tribunal de Justiça do Estado de São Paulo: Por que não?
}

\author{
Tempo Rei! \\ Oh Tempo Rei! \\ Transformai \\ As velhas formas do viver \\ (GILBERTO GIL)
}

O trecho da canção acima faz emergir uma reflexão referente à dicotomia que o tempo propõe, no sentido de que apesar de todo dia o tempo ser novo, ele é o mesmo que sempre existiu. Apesar de todos os dias haver oportunidade de viverem novas coisas, rotineiramente a sociedade reproduz os mesmos vícios que fluem das velhas formas de viver. A luz dessa reflexão, quando se pensa o ser humano em sociedade a depender de seu sexo ou de sua cor, o que se encontra são formas impregnadas por sentidos que reportam às velhas formas de viver carregadas pela repetição de vícios passados ao determinar a forma de ser desses sujeitos, seus espaços, deveres, papéis e limitam direitos.

Assim, apesar das inúmeras conquistas nos últimos tempos, o acesso de mulheres a cargos de comando ainda sofre barreiras veladas e sutis. Tomemos como exemplo o Poder Judiciário do Estado de São Paulo que segundo dados, no ano de 2017 a primeira instância era constituída por 1.184 juízes que atuavam na capital e 1.363 que atuavam no interior de São Paulo, ou seja, ao todo havia 2.547 juízes atuando em São Paulo (SIC-TJ/SP, 2017). Dentre os magistrados que estão na capital de São Paulo 373 são juízas e 340 são juízes de $1^{\circ}$ grau, há 61 juízes substitutos no $2^{\circ}$ grau, 21 juízas substitutas no $2^{\circ}$ grau, 361 desembargadores e 28 desembargadoras.

Com a finalidade de compreender melhor o quadro atual tecido acima, é importante resgatar como se deu o ingresso de magistradas no Tribunal de Justiça de São Paulo. Segundo dados do TJ-SP o ingresso de mulheres na magistratura de primeiro grau, iniciou em 1980 com o $146^{\circ}$ Concurso de Ingresso na Magistratura quando dos 71 aprovados 68 eram homens, 95,77\%, e três eram mulheres, 4,23\% (TJSP, 2019). Ou seja, nos 145 concursos anteriores, não houve ingresso de mulheres, mas tão somente homens.

Importante salientar que, o ingresso dessas mulheres se deu em razão de pressão da Comissão da Mulher Advogada da $\mathrm{OAB} / \mathrm{SP}$, pois a época, o concurso de ingresso à magistratura, identificava os/as candidatos/as em todas as fases, o que consequentemente era instrumento que permitia, sutilmente, que mulheres não passassem no concurso para magistradas (MELO 2015, p. 2). 
A positivação de mecanismo legal coibindo tal identificação surgiu em 1995 quando o Tribunal de Justiça paulista encaminhou à Assembleia Legislativa projeto de lei referente ao processo de seleção para a Magistratura no Estado (PL-726/95) que resultou na Lei 9351/96 vedando, no artigo $1^{\circ}$, a identificação das pessoas nas duas primeiras fases.

Em complemento ao exposto, segue tabela colacionada abaixo, que indica o número de mulheres e homens ingressantes na magistratura tendo como marco o certame que ingressou as primeiras mulheres. Esta tabela viabiliza observar que houve um aumento significativo de mulheres no concurso da magistratura após a movimentação da comissão mulher advogada $\mathrm{OAB} / \mathrm{SP}$, pois antes desse período, não ingressou nenhuma mulher.

Tabela 1 - Ingresso na magistratura de São Paulo por décadas

\begin{tabular}{|l|l|l|l|l|l|l|l|}
\hline Concurso & Ano & Inscritos (as) & Aprovados (as) & Homem & M & Mulher & $\%$ \\
\hline $\mathbf{1 4 6}^{\circ}-\mathbf{1 5 9}^{\circ}$ & $1980-1990$ & 20.386 & 826 & 739 & $89,46 \%$ & 86 & $10,58 \%$ \\
\hline $\mathbf{1 6 0}^{\circ}-\mathbf{1 7 3}^{\circ}$ & $1990-2000$ & 42,566 & 948 & 543 & $57,27 \%$ & 405 & $42,73 \%$ \\
\hline $\mathbf{1 7 4}^{\circ}-\mathbf{1 8 7}^{\circ}$ & $2001-2018$ & 122,551 & 1,224 & 717 & $58,57 \%$ & 507 & $41,43 \%$ \\
\hline
\end{tabular}

Fonte: Comunicação Social TJSP, 2019.

O conjunto de informações tecidas acima demonstra que, homens tem índice maior de aprovação. Contudo, há número equânime de mulheres na magistratura de primeira instância do Estado de São Paulo se comparado aos homens. Quando se volta à atenção ao quadro de desembargadores do TJ-SP em 2017, verifica-se que há 361 desembargadores, dos quais apenas 28 são mulheres. Quanto aos desembargadores substitutos, o número é de 61 homens e 21 mulheres (Sic-TJ/SP, 2017), ou seja, apesar do número de magistradas serem maior, esta realidade não se reflete no Tribunal.

Quando observado a presença de mulheres na magistratura em âmbito Nacional, o que se percebe é que o percentual de mulheres magistradas é inferior ao de magistrados. Se observado separadamente os ramos da justiça brasileira, em âmbito Estadual, o percentual de mulheres é de $34,5 \%$ e de homens $65,5 \%$. Essa diferença cresce ainda mais quando se analisa os tribunais e conselhos superiores, cujo percentual é respectivamente $27,8 \%$ de mulheres e 72,2\% de homens; e 26,1\% de mulheres e 73,9\% de homens (CNJ. 2014 p. 36 e 37).

Importante salientar que a nomeação de mulheres ao TJ-SP é algo recente que iniciou em 1997, quando ingressou a primeira mulher ao Tribunal de Alçada, pelo chamado Quintos Constitucionais, ocasião em que um desembargador paulista em entrevista à rádio, disse entender que a mulher deveria ficar em casa, cuidando do fogão, pois havia dias em que ficaram "perturbadas" e que tais fatos atrapalhavam a carreira (MELO 2005, p. 2). 
Após essa primeira ingressante ao TJSP, a próxima nomeação veio ocorrer em 2003. Portanto, de 1997 a 2002, havia 129 desembargadores e uma única desembargadora, Luzia Galvão Lopes da Silva que ingressou pelo Quinto Constitucional em 1997, tendo se aposentado no início de 2003. No final de 2003 foi nomeada a segunda desembargadora do TJ-SP, Isabela Gama de Magalhães Gomes, que também ingressou pelo Quinto Constitucional (TJSP, 2018).

Dados do TJ-SP informam que no período entre 1997, quando a primeira desembargadora foi nomeada, até 2017, foram nomeados para compor a segunda instância 213 homens e 28 mulheres. Desde a criação do TJ-SP em 1874 até 2017 passaram pelo tribunal 1.219 desembargadores e 35 desembargadoras. Quanto à presidência do TJ-SP, está só foi ocupada por homens e brancos (TJSP, 2019). Como forma de ilustrar o exposto a tabela abaixo foi formulada. Esta informa o ingresso de mulheres no Tribunal por ordem cronológica de 1997 a 2017.

Tabela 2 - Ingresso de Mulheres no TJSP de 1997 a 2017

\begin{tabular}{|c|c|}
\hline $\begin{array}{l}\text { NOME DE MULHERES QUE COMPUSSERAM O TJSP } \\
\text { ENTRE } 1997 \text { E } 2017\end{array}$ & $\begin{array}{l}\text { DATA DE INGRESSO E INDICAÇÃO DE } \\
\text { CARREIRA }\end{array}$ \\
\hline Luzia Galvão Lopes Da Silva & $\begin{array}{l}\text { 12.03.1997. Quinto constitucional. Aposentada } \\
\text { 09.04.2003. }\end{array}$ \\
\hline Isabela Gama De Magalhães Gomes & $\begin{array}{l}\text { 19.03.2003. Quinto constitucional. Aposentada } \\
\text { 02.02.2010. }\end{array}$ \\
\hline Berenice Marconde Cesar & 03.01.2005. \\
\hline Zélia Maria Antunes Alves & 03.01.2005. Aposentada 09.02.2015. \\
\hline Constança Gonzaga Junqueira De Mesquita & 27.04.2005. Aposentada 24.05.2011. \\
\hline Teresa Cristina Motta Ramos Marques & 22.05 .2005 \\
\hline Angelica De Maria Mello De Almeida & 03.01.2005. Quinto constitucional. \\
\hline Rosa Maria Barreto Borriello De Andrade Nery & $\begin{array}{l}\text { 03.01.2005. Quinto constitucional. Aposentada } \\
\text { 25.02.2015. }\end{array}$ \\
\hline Maria Cristina Zucchi & 03.01.2005. Quinto constitucional. \\
\hline Regina Zaquia Capistrano Da Silva & $\begin{array}{l}\text { 03.01.2005. Quinto constitucional. Aposentada } \\
\text { 29.08.2012. }\end{array}$ \\
\hline Maria Tereza Do Amaral & 03.01.2005. Quinto constitucional. \\
\hline Ligia Cristina De Araujo Bisogni & 24.03.2005. Quinto Constitucional. \\
\hline Ana De Lourdes Coutinho Silva Da Fonseca & 09.06.2005. Quinto Constitucional. \\
\hline Vera Lúcia Angrisani & 08.11.2005. Quinto Constitucional. \\
\hline Sílvia Rocha & 09.06.2010 \\
\hline Sandra Maria Galhardo Esteves & 04.08.2010. Quinto Constitucional. \\
\hline Maria Beatriz Dantas Braga & 18.05.2011. \\
\hline Maria Olivia Pinto Esteves Alves & 30.11 .2011 \\
\hline Maria De Lourdes Rachid Vaz De Almeida & 04.04 .2012 \\
\hline Christine Santini & 24.10 .2012 \\
\hline Mary Grün & 04/10/2013. Quinto Constitucional. \\
\hline Luciana Almeida Prado Bresciani & 25.09.2013. \\
\hline
\end{tabular}




\begin{tabular}{|l|l|}
\hline Maria Cristina Cotrofe Biasi & 30.10 .2013$. \\
\hline Mônica De Almeida Magalhães Serrano & $04 / 10 / 2013$. Quinto Constitucional. \\
\hline Ana Luiza Liarte & 02.04 .2014 \\
\hline Cláudia Grieco Tabosa Pessoa & 02.07 .2014$. \\
\hline Maria Laura De Assis Moura Tavares & 21.05 .2014$. \\
\hline Maria Lúcia Ribeiro De Castro Pizzotti Mendes & 27.08 .2014$. \\
\hline Ana Catarina Strauch & 25.04 .2014$. Quinto Constitucional \\
\hline Daise Fajardo Nogueira Jacot & 01.10 .2014$. \\
\hline Flora Maria Nesi Tossi Silva & 11.03 .2015$. \\
\hline Lucila Toledo Pedroso De Barros & 18.02 .2016$. \\
\hline Jonize Sacchi De Oliveira & 21.03 .2016$. Quinto constitucional. \\
\hline Denise Andréa Martins Retamero & 22.02 .2017$. \\
\hline Kenarik Boujikian & 08.11 .2017$. \\
\hline
\end{tabular}

Fonte: Livro digital do Tribunal de justiça do Estado de São Paulo e seus desembargadores.

A tabela acima demonstra que as nomeações não observaram equidade de gênero. $O$ baixo número de mulheres desembargadoras no TJ-SP bem como a ausência de mulheres na presidência é nomeado por Mônica de Melo como “[...] fenômeno da masculinização do comando e de feminização da subalternidade [...]”. Ou seja, mesmo nos espaços conquistados pelas mulheres, “[...] o poder de mando permanece na fiel lógica da cultura masculina $[. .$.$] "$ (MELO, 2005, p. 3).

Conforme Anne Biogeol (2005), o acesso de mulheres aos cargos considerados de cúpula na magistratura é minado por uma espécie de telhado de vidro, que funciona na prática como um mecanismo capaz de dificultar, e por vezes barrar, o acesso de mulheres às instâncias superiores. Ora, combinar merecimento com antiguidade para efeitos de promoção é uma forma de evitar que determinado grupo chegue a determinado espaço (2013). A autora conclui que, apesar da entrada e presença feminina na magistratura não ser mais questionada de maneira explícita, há um mecanismo sutil que barra sua ascensão às posições hierarquicamente superiores (Ibidem, p. 6).

É possível confirmar esta afirmação se tomarmos por base os nomeados ao Tribunal em 2005. A maioria deles havia ingressado na magistratura em 1980, tendo a antiguidade sido um dos critérios para promoção, tal como exige a lei. No entanto, entre os novos desembargadores havia trinta e quatro homens e apenas uma mulher, Zélia Maria Antunes Alves. Este é um claro exemplo do referido "telhado de vidro", uma vez que o critério da antiguidade por muito tempo será um dificultador do acesso de mulheres ao mais alto posto do Judiciário Estadual. Pois é necessário considerar que as primeiras mulheres só ingressaram na magistratura paulista em 1980 (106 anos depois da criação do TJ-SP) no $146^{\circ}$ concurso da 
magistratura. Assim, o que aparenta ser um critério isenta e isonômico na verdade fere o princípio da igualdade material.

Portanto, por mais que mulheres seja maioria na base da carreira da magistratura, o critério antiguidade e merecimento previsto na Constituição, quando lidos a partir da igualdade formal, funcionará como verdadeiro perpetuador de desigualdades.

\section{Onde estão as Mulheres Negras?}

Considera-se que a presente reflexão deve se iniciar a partir da compreensão de que a democracia racial proclamada é um verdadeiro sofismo. A este respeito, Oliveira afirma que apesar de haver uma diversidade racial amplamente percebida na sociedade, não há oportunidades nem igualdade a direitos e, o próprio Estado apoia-se sobre o paradigma dominação/submissão que impregna a sucessão das gerações e pauta as diferenças de gênero. Tudo isso, faz com que o preconceito não se constitua majoritariamente por meio de características negativas, mas por vias da negação de características positivas aos grupos discriminados (OLIVEIRA, 2002, p. 34).

Nesta toada, é possível considerar que o preconceito sutil é o que trabalha mais profundamente na nossa sociedade, arraigado no pré-consciente pela ideologia dominante que Marilena Chauí entende como "elaboração intelectual incorporada pelo senso comum social de ocultar e dissimular as divisões sociais e políticas dar-lhes aparência de indivisão e de diferenças naturais entre os seres humanos" (CHAUÍ, 1999, p. 174).

A consequência disso é a inversão, a posição dos efeitos no lugar das causas; a produção do imaginário social transformando imagens diretas e imediatas da experiência social em um conjunto coerente, lógico e sistemático de ideias, o silêncio e a bipolaridade cega reconhecidos na forma simplista do senso comum de refletir a relação de poder vinculada a ideia de feminino e masculino apenas tendo como base as questões eminentemente biológicas que caracterizam os dois sexos.

É exemplo de inversão de causas e efeitos as categorias raça e desigualdades sociais, quando se sustenta que em razão das desigualdades sociais decorrem as diferenças de raça. Tais argumentos ofuscam as reais determinantes das desigualdades, invertendo as causas e os efeitos. É preciso considerar que diante da racialização das pessoas se determina seus direitos e suas possibilidades gerando assim, desigualdades de direitos e diferenças sociais, que são os efeitos da discriminação. 
Nesta toada, Adilson José Moreira afirma que, discriminar é categorizar negativamente pessoas a partir de característica ou situação jurídica para atribuir a elas consequências que as afastam de possibilidades iguais (MOREIRA, 2017, p. 27).

Nas instituições jurídicas, percebe-se que o ato de discriminar, atua pela sutileza de não se desenvolver medidas necessárias e efetivas sob o manto da democracia racial ou meritocracia. Logo, o não fazer políticas eficazes para promoção da igualdade fere o “[...] direito fundamental a não discriminação [...]" que encontra respaldo no direito à igualdade (Ibidem, p. 21), visto que o racismo não precisa do fazer, para que ele continue perpetuando, pois, para sua manutenção, basta o não fazer.

No que tange às mulheres negras, verifica-se que sobre elas recaem uma intersecção de violências gerando um aprofundamento das desigualdades de acesso à Direitos. Por tais razões, com a finalidade de compreender as violências que atingem as mulheres negras é necessário voltar à atenção a estas sem tratá-las como participantes de um grupo maior de mulheres.

A este respeito à autora Kimberlé Crenshaw observa que mulheres são, dentro da sociedade, um grupo que sofre violências de gênero. Contudo, na construção de mecanismos à proteção destas, é necessário se atentar as especificidades dentro do conjunto de mulheres, uma vez que há aquelas que são marcadas por diversas interseções de violências, decorrentes de raça, etnia, idade, classe e estado civil. Portanto, para a construção de soluções ou para compreender o cenário em que essas mulheres estão inseridas, apenas o critério de gênero pode fazer com que algumas discriminações passem despercebidas. Como forma de ilustrar o exposto, a autora apresenta a experiência das mulheres dalit e, assim aponta que:

[...] Pode ser resgatado da experiência das mulheres dalit, na Índia, que são espancadas ou sofrem outras formas de abuso em espaços públicos quando realizam suas responsabilidades 'femininas', como buscar água na fonte. Ou seja, os abusos ocorrem em contextos em que a suposta condição de 'intocável' as deixa vulneráveis à violência dos membros das castas mais altas, principalmente se estes considerarem que elas transgrediram suas fronteiras corporais. Embora essa violência seja prontamente definida como simples discriminação de casta, na verdade, ela é interseccional: as mulheres devem, portanto, negociar um conjunto complexo de circunstâncias nas quais uma série de responsabilidades marcadas pelo gênero as posiciona de forma que elas absorvam as consequências da discriminação de casta na esfera pública (CRENSHAW, 2002, p. 176).

Correlacionando o exposto, ao contexto do estudo, é possível considerar que as diferenças decorrentes de raça estabelecem limites corporais e circunstanciais ainda na contemporaneidade que interferem nas reais possibilidades de acesso à determinados espaços de poder e decisão, que no caso em estudo é a magistratura e o TJ-SP às mulheres negras. 
Estes limites estabelecem hierarquias que exige esforço desigual a depender do corpo e da cor a qual é formada

De acordo com o Ministério das Relações Exteriores o Brasil é o país que tem a maior população negra, atrás apenas da Nigéria (2010). Atualmente a população negra no Brasil é de 54\% da população (CUT, 2010, p. 2). Em 2005, os negros (pardos e pretos) correspondiam a metade da população do país, sendo que 35,8 milhões residiam na Região Nordeste e 32 milhões, no Sudeste. O Estado de São Paulo contava com 12,5 milhões de pessoas pretas e pardas, o que correspondia a $32 \%$ dos seus habitantes, segundo dados divulgados pela Pesquisa Nacional por amostra de domicílios - PNAD (SEADE, 2005, p. 1).

Apesar da paridade numérica entre a população branca e negra, dados do CNJ apontam para o fato de que, em 2014, apenas $15 \%$ dos magistrados eram negros (AMAERJ, 2017). Ou seja, apesar do ser o segundo país mais negro do mundo, os negros são minorias no poder judiciário e, apesar da maioria dos integrantes da magistratura em primeira instância ser mulheres, quem são essas mulheres?

Gráfico 1 - Retrato da magistratura Paulista na primeira instância

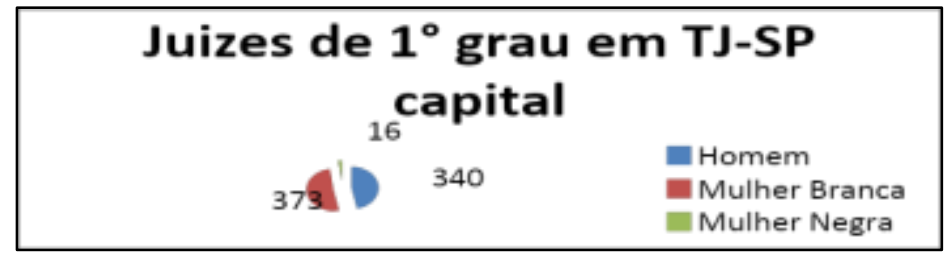

Fonte: Sic-TJ/SP, 2017.

O gráfico com recorte da capital paulista demonstra que essas mulheres são majoritariamente brancas, sendo a população negra, Trans e indígena praticamente inexistente nestes espaços. Este não é um caso particular da cidade de São Paulo. Segundo dados, a âmbito Nacional, no que diz respeito à raça, de 1995 a 2013 o número de magistrados negros na justiça Estadual representa o percentual de 15,6\% e os indígenas são 0,1\% no Brasil (CNJ, 2014, p. 42) e não há dados quanto a população Trans. Ampliando o campo de análise para todos os ramos da justiça, ou seja, tanto justiça comum como especial, em censo realizado pelo CNJ em 2014 constatou que o percentual de magistrados negros no Brasil é de 19,1\% (CNJ, 2014, p. 38, 39).

Voltando os olhos ao âmbito Estadual, de forma mais específica o TJ-SP, a partir do fundamento de raça, o censo do Poder judiciário/TJ-SP, em 2013 constatou que 96,6\% dos magistrados se autodeclaram brancos e 3,2\% se autodeclaram pretos ou pardos, ou seja, há 
uma menor representatividade da população negra se comparada aos dados Nacionais. A partir das informações expostas, é possível concluir que a população negra é minoritária na Justiça brasileira, no entanto, questiona-se onde estão as mulheres negras? Pois os dados supramencionados não interseccionam raça e gênero o que pode ocultar uma intersecção de violências que são particulares, a mulher negra (CRENSHAW 2002, p. 177).

Diante da escassez de dados que olhem a intercessionalidade do tema, fora solicitado ao sistema de informação ao cidadão (Sic) junto ao site o TJ-SP, o qual disponibilizou algumas informações e a partir deles foi possível criar a seguinte tabela.

Tabela 3 - Quadro de mulheres negras na magistratura de São Paulo até 2017

\begin{tabular}{|l|l|l|}
\hline \multicolumn{2}{|c|}{ QUADRO DE MAGISTRATURA PRETA 2017 } \\
\hline Cargo/Raça & Negra & Parda \\
\hline Desembargadora & 1 & 3 \\
\hline Juíza de Direito & 6 & 10 \\
\hline
\end{tabular}

Fonte: Sic-TJ/SP, 2017.

Os dados corroboram que, apesar da população negra corresponder a $32 \%$ da população de São Paulo, na magistratura paulista há 20 juízas negras dentre os 2.547 juízes. No âmbito do Tribunal, 4 são desembargadoras negras em um quadro de 471 desembargadoras e desembargadores incluso os substitutos (SIC-TJ/SP, 2017). Tal cenário evidência que a estrutura de desigualdade que a mulher negra está inserida é diferente da mulher branca, pois, apesar dos cargos de cúpula serem mais ocupados por homens, existe 24 mulheres brancas no TJ-SP, das quais apenas 4 são negras. Importante ressaltar que tais dados foram levantados por meio de autodeclaração, não obrigatória, em fichas do próprio TJ-SP.

É importante salientar que o número reduzido de mulheres negras em espaços de poder, decorre da negação de acesso à educação fundamental e básica pelo regulamento 22/1887, bem como pela dificuldade de acesso à educação superior, vez que apesar das faculdades terem sido implantadas no Brasil desde 1808, era permitida aos homens. Em 19 de abril de 1879 o Decreto $\mathrm{n}^{\circ} 7.247$ permitiu mulheres acessarem o ensino superior, mas só as mulheres brancas estavam em condições de o cursarem, pois a população negra no geral só acessou educação básica muito depois.

Como reflexo desses fatos, dados do IBGE de 2010 da Cidade de São Paulo, dão conta de evidenciar que esse abismo criado ainda se mantém na realidade ao informar que 186.952 pessoas que se autodeclaram brancas entre 18 e 24 anos de idade estavam frequentando o ensino superior e 50.069 que se declararam pretos com igual idade estavam frequentando a 
universidade em 2010, ou seja, a população branca é quase quatro vezes superior à população negra nas universidades (IBGE, 2010).

Os dados acima revelam que a democracia racial é um engano, o que existe é uma desigualdade e um racismo estrutural. Quanto a inexpressiva quantidade de negras no tribunal encontra explicação histórica e se mantém porque a população negra continua sendo negligenciada quanto a direitos sociais básicos como a educação, pois o ter poucas negras no tribunal se dá em razão de que elas são poucas na magistratura e elas são poucas na magistratura porque tem maior dificuldade de acessar a educação superior diante das barreiras que historicamente se mantém e isso é racismo estrutural, que causa discriminação no acesso a direitos iguais. Nesse sentido Djamila Ribeiro expõe que:

\begin{abstract}
Para a população negra não se criou mecanismos de inclusão. Das senzalas fomos para as favelas. Se hoje a maioria da população negra é pobre, é por conta dessa herança escravocrata e por falta da criação desses mecanismos. É necessário conhecer a história deste País para entender por que certas medidas, como ações afirmativas, são justas e necessárias. Elas precisam existir justamente porque a sociedade é excludente e injusta para com a população negra. Cota é uma modalidade de ação afirmativa que visa diminuir as distâncias. O racismo institucional impede a mobilidade social e o acesso da população negra a esses espaços (DJAMILA. 2015).
\end{abstract}

\title{
Conclusão
}

Se é pra vencer deixa quem sabe fazer Eu tô na luta, sou mulher

Posso ser o que eu quiser. (KAROL CONK: Tô na luta)

Poder ser o que quiser, exige pensar e programar mecanismos que promovam igualdade de fato. Para tanto, é preciso olhar gênero e raça na formulação de políticas públicas. Quanto ao judiciário, é necessário ampliar o ingresso de mulheres, principalmente de mulheres negras e indígenas.

No Poder Judiciário, o número de mulheres ocupantes de cargos nos tribunais é imensamente inferior ao de homens. Quando se verifica que o critério de ascensão é merecimento e antiguidade, têm-se a conjunção perfeita para a manutenção da discriminação. Merecimento é um critério que sempre carrega alguma subjetividade e antiguidade é um critério que objetivamente prejudica as mulheres, uma vez seu ingresso na magistratura só foi permitido muito tempo depois dos homens. Portanto, há muito mais homens em condição de ascender por esse critério do que mulheres. 
Quando a atenção se volta às mulheres negras, aí sim a disparidade é inadmissível. Homens e mulheres negras é minoria na magistratura em geral, o que decorre da condição de não detentor de dignidade que a população negra historicamente foi relegada durante e pósescravidão no Brasil. Na situação de escravos, não tinham acesso à nenhum direito e, mesmo depois da abolição, seguiam tratados como cidadãos de segunda categoria, cujo acesso às condições mínimas de dignidade, como o acesso à educação, eram negados ou dificultados em razão da racialização imposta, o que justificava ser essa população detentora de menos direitos.

Com base nestas duas formas de hierarquização social se desenha o retrato atual do TJ-SP que é formado, majoritariamente, por homens brancos. É necessário pensar em mecanismos que promovam igualdade de fato para ampliar o ingresso de mulheres em geral, e de mulheres negras em especial, na primeira instância e na cúpula do Poder Judiciário.

O que se depreende do presente estudo é que embora o direito à igualdade esteja solidamente expresso na Constituição, ainda nos resta o desafio é dar-lhe concretude e, para isso, é preciso rever os atuais critérios de nomeação da cúpula do Judiciário. Faz-se urgente a criação de cotas raciais e de gênero as quais são necessárias para que, em breve, gênero e raça se encontrem em situação equânime de participação em todas as instâncias de Poder Judiciário respeitando, com isso, o princípio de igualdade material previsto constitucionalmente.

\section{Referências}

AMAERJ - Associação de magistrados. $1^{\circ}$ Encontro nacional de juízes e juízas negras, Rio de Janeiro, 2017. Disponível em: <http://amaerj.org.br/noticias/1o-encontro-nacional-dejuizas-e-juizes-negros-esta-com-inscricoes-abertas/> . Acessado em 08/09/2017.

ANDRADE, Tânia. Mulheres no mercado de trabalho: onde nasce a desigualdade? Estudo técnico para consulta Legislativa realizada pela $V$ área de Direito do Trabalho e Processual do Trabalho, 2016, p 72. Disponível em: <http://www2.camara.leg.br/acamara/documentos-e-pesquisa/estudos-e-notas-tecnicas/areas-daconle/tema7/2016_12416_mulheres-no-mercado-de-trabalho_tania-andrade>. Acessado em 01/11/2017.

AZEVEDO, Janaina. Negros no Mundo. Laboratório de demografia e estudos populacionais da universidade Juiz de Fora, 2010. Disponível em: <http://www.ufjf.br/ladem/2010/01/24/negros-do-mundo/> . Acessado em 02/11/2017.

BOBBIO. Norberto. A era dos Direitos. Tradução Carlos Nelson Coutinho - Nova edição Editora Elsevier. Rio de Janeiro, 2004, p. 97. 
BOIGEOL, Anne. Las mujeres y la corte. La difícil implementación de la igualdad de sexos en el acceso a la magistratura. Revista sobre Enseñanza del Derecho de Buenos Aires, Año 3 , número 6, 2005, p. 03-25.

BOIGEOL, Anne. Feminisation of the French Magistrature, between Parity and

Disparities. Conferência realizada a 18.06.2013, na Assembleia da República de Lisboa Portugal, no âmbito da sessão "As mulheres nas profissões jurídicas: experiências europeias" do Colóquio "As mulheres nas magistraturas: percursos e desafios". 2013. Disponível em: $<$ http://saladeimprensa.ces.uc.pt/?col=canalces\&id=8185>. Acessado em 01/10/2017.

BONELLI, Maria da Gloria; CUNHA, Luciana G; OLIVEIRA, Fabiana L. de e SILVEIRA, Maria Natália B. da. Profissionalização por gênero em escritórios paulistas de advocacia. Tempo Social revista de sociologia da USP, v. 20, n. 1. Junho 2008, p. 265-290. Disponível em: <http://www.scielo.br/pdf/ts/v20n1/a13v20n1

$>$. Acesso em 29/03/2020.

BRASIL. Tribunal Superior Eleitoral - TSE. Mulheres representam 52\% do eleitorado brasileiro. Disponível em: <http://www.tse.jus.br/imprensa/noticiastse/2018/Marco/mulheres-representam-52-do-eleitorado-brasileiro>. Acessado em 24/03/2018.

BRASIL. Conselho Federal da Ordem dos Advogados do Brasil. Quadro geral de advogados. Disponível em:

<http://www.oab.org.br/institucionalconselhofederal/quadroadvogados >. Acessado em 24/03/2018.

BRASIL. Conselho Federal da Ordem dos Advogados do Brasil. Memorial galeria de presidentes. Disponível em:<http://www.oabsp.org.br/portaldamemoria/galeria-depresidentes $>$. Acessado em 24/03/2018.

BRASIL. Censo do poder judiciário: VIDE: Vetores iniciais e dados estatísticos. Conselho Nacional de Justiça - CNJ - Brasília, 2014, p. 212. Disponível em:

<http://www.cnj.jus.br/images/dpj/CensoJudiciario.final.pdf>. Acessado em 05/11/2017.

BRASIL. Decreto ${ }^{\circ} 21.076$ de 24 de fevereiro 1932. Código Eleitoral. Disponível em: $<$ http://www2.camara.leg.br/legin/fed/decret/1930-1939/decreto-21076-24-fevereiro-1932507583-publicacaooriginal-1-pe.html>. Acessado em 23/10/2017.

BRASIL. Instituto Brasileiro de Geografia e Estatística, censo demográfico - sistema nacional de informação. Total de pessoas brancas entre 18 e 24 anos de idade que frequentam o ensino superior. Disponível em: <http://cidades.ibge.gov.br/cartograma/mapa. php?lang $=\& \operatorname{coduf}=35 \& \operatorname{codmun}=350950 \&$ idtema $=132 \& \operatorname{cod} \mathrm{v}=\mathrm{v} 42 \& \operatorname{search}=\mathrm{sao}-$ paulo|campinas|sintese-das-informacoes-2010> . Acessado em 20/07/2017.

BRASIL. Secretária de Combate ao Racismo, p.2. Disponível em: < https://cut.org.br/system/uploads/action_file_version/1fcd516c53da22deaee03e41c795da50/fi le/dados-20-20-20-20-20-20-20populacao-20negra-20no-20brasil-20-20populacao.pdf $>$. Acessado em 10/11/2017. 
CARNEIRO, Sueli. Enegrecer o Feminismo: a Situação da Mulher Negra na América Latina a partir de uma perspectiva de Gênero, 2011, p. 5. Disponível em: < https://www.geledes.org.br/enegrecer-o-feminismo-situacao-da-mulher-negra-na-americalatina-partir-de-uma-perspectiva-de-genero/ > . Acessado em 20/10/2017.

CARNEIRO, Sueli. Racismo, sexismo e desigualdade no Brasil. São Paulo: Selo negro, 2011, p. 16.

CRENSHAW, Kimberlé W. Documento para o encontro de especialistas em aspectos da discriminação racial relativos ao gênero. Estudos Feministas, 10 (1): 171-188 2002.

Disponível em: <https://www.revistas.usp.br/ts/article/viewFile/84979/87743 >. Acessado em 24/03/2018.

DE BEAUVOIR. Simone. O segundo sexo. Difusão Europeia do Livro, São Paulo. $4^{\circ}$ Edição, 1970, p. 309.

FERNANDES. Florestan. A integração do negro na sociedade de classes Vol. 1.5 ed. : São Paulo. Editor Globo, 2008. p. 31.

FERNANDES. Florestan. A integração do negro na sociedade de classes Vol. 1.5 ed. : São Paulo. Editor Globo, 2008. p. 31.

MELO Mônica de. A Participação da Mulher na Magistratura Brasileira. Revista Jurídica Virtual - Brasília, vol. 6, n. 70, mar. 2005. Disponível em:

$<$ https://revistajuridica.presidencia.gov.br/index.php/saj/article/view/539/1105>. Acessado em 19/10/2017.

MOREIRA, Adilson José. O que é discriminação? - Belo Horizonte (MG): Letramento: Casa do Direito: Justificando, 2017, p. 198.

ORTEGAL, Leonardo. Relações raciais no Brasil: colonialidade, dependência e diáspora. Serv. Soc. Soc. São Paulo, n. 133, p. 413-431, dez. 2018 p. 417.

NABUCO, Joaquim. O abolicionismo. São Paulo: Publifolha, 2000, p. 104, p. 14.

PINTO, Célia Regina Jardim. Feminismo, história e poder. Revista Social e

Política. vol.18 no. 36 Curitiba June 2010. Disponível em: <

http://www.scielo.br/scielo.php?script=sci_arttext\&pid=S0104-

$44782010000200003 \& \operatorname{lng}=\mathrm{en} \& \mathrm{nrm}=\mathrm{iso} \& \mathrm{t} \operatorname{lng}=\mathrm{pt}>$. Acessado em 01/07/2018

RIBEIRO, Djamila. Ser contra cotas raciais é concordar com a perpetuação do racismo, 2015. Disponível em: <https://www.cartacapital.com.br/sociedade/ser-contra-cotas-raciais-econcordar-com-a-perpetuacao-do-racismo-1359.html>. Acessado em 11/09/2017.

SÃO PAULO. Censo do Poder Judiciário: Tribunal de Justiça do Estado de São Paulo, magistrados. Conselho Nacional de Justiça - CNJ, 2013, p. 18. Disponível em: < http://www.cnj.jus.br/files/conteudo/arquivo/2017/07/0dc09a2d5e63f6bf0d83ea9aeaa82853.p df $>$. Acessado em 20/11/2017. 
SÃO PAULO. Decreto $\mathrm{n}^{\circ} 7.247$ de 19 de abril de 1879 . Reforma o ensino primário e secundário no município da corte e o superior em todo império. 1879. Disponível em: <http://www2.camara.leg.br/legin/fed/decret/1824-1899/decreto-7247-19-abril-1879-547933publicacaooriginal-62862-pe.html>. Acessado em 23/10/2017

SÃO PAULO. Fundação do Sistema de Análise de Dados - SEADE. A maior população negra do país, 2017. Disponível em:

<http://produtos.seade.gov.br/produtos/idr/download/populacao.pdf > . Acessado em 10/08/2017.

SÃO PAULO. Lei 9.351/96. Dispõe sobre o concurso de ingresso na Magistratura da Justiça Comum do Estado de São Paulo. 1996. Disponível em: <https://governosp.jusbrasil.com.br/legislacao/172897/lei-9351-96>. Acessado em 10/10/2017.

SÃO PAULO.Regulamento de 22 de agosto de 1887 da província do Estado de São Paulo. Regulamento para instrucção publica Provincial 1887. Disponível em: < http://www.usp.br/niephe/bancos/legis_detalhe.asp?blg_id=205>. Acessado em 23/10/2017.

SÃO PAULO. Serviço de Informação ao Cidadão - Sic/TJSP, 2017. Disponível em: <http://www.tjsp.jus.br/CanaisAtendimentoRelacionamento/FaleConosco>. Acessa em 02/12/2017.

SÃO PAULO. Tribunal de Justiça do Estado de São Paulo - TJ/SP. Quem somos? 2019. Disponível em: <http://www.tjsp.jus.br/QuemSomos/Presidencia>. Acessado em 07/11/2019.

SÃO PAULO. Tribunal de Justiça do Estado de São Paulo. Galeria de Ex-Presidentes do Tribunal de Justiça de São Paulo - 1874 a 2015. Disponível em: < http://www.tjsp.jus.br/QuemSomos/ExPresidentes>. Acessado em 10/11/2017.

SÃO PAULO. Tribunal de Justiça do Estado de São Paulo. O Tribunal de Justiça de São Paulo e seus Desembargadores, 2017. Disponível em:

<http://www.tjsp.jus.br/Download/Biblioteca/Curriculum/Curriculum.pdf >. Acessado em 05/11/2017.

SÃO PAULO. Tribunal de Justiça do Estado de São Paulo - TJSP, 2017. Quem somos. Disponível em: <http://www.tjsp.jus.br/QuemSomos> Acessado em 23/10/2018.

SÃO PAULO. Tribunal de Justiça do Estado de São Paulo - TJSP. Notícias: Raio-x da representatividade da mulher na Justiça paulista , 2019. Disponível em: < http://www.tjsp.jus.br/Noticias/Noticia?codigoNoticia=55993\&pagina=1>. Acessado em 08/03/2019.

SILVA, Kalina Vanderlei; SILVA, Maciel Henrique. Dicionário de Conceitos Históricos. Editor Contexto - 2. ed., $2^{a}$ reimpressão. São Paulo, 2009, p. 439. Disponível em: $<$ https://efabiopablo.files.wordpress.com/2013/04/dicionc3a1rio-de-conceitoshistc3b3ricos.pdf>. Acessado em 29/11/2017.

SCOTT, Joan. Gênero: uma categoria útil de análise histórica. Revista Educação \& Realidade, v.1., n.2, jul./dez. 1990, traduzido da versão em francês. Disponível em: < http://www.seer.ufrgs.br/educacaoerealidade/article/view/71721/40667 >. Acessado em 05/07/2018. 